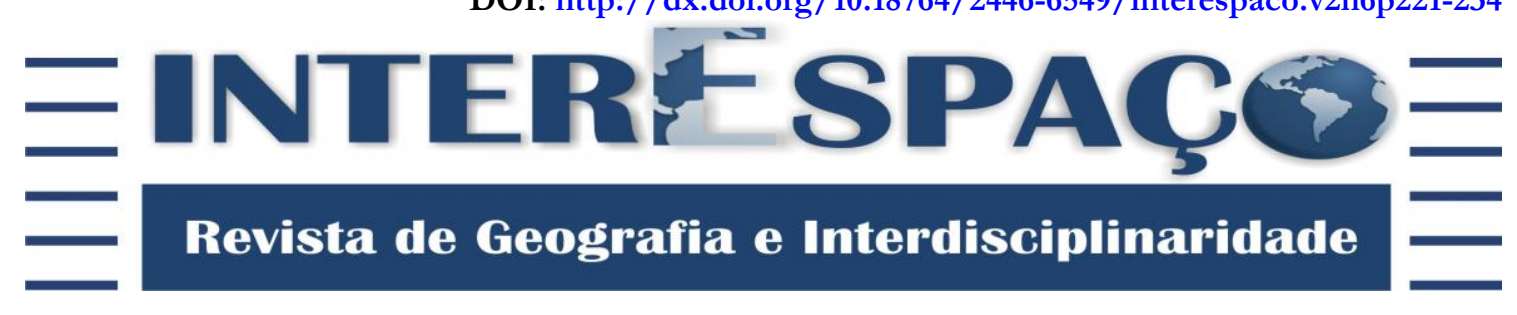

\title{
FRAGILIDADE AMBIENTAL NA BACIA DO CÓRREGO ÁGUA BRANCA, OESTE MARANHENSE
}

\author{
Raifran Abidimar de Castro \\ Mestre em Geografia pela Universidade Federal do Pará - UFPA. Professor de \\ Geografia do Instituto Federal do Maranhão - IFMA/Campus de Açailândia. \\ raifrancastro@ifma.edu.br
}

\begin{abstract}
RESUMO
Os estudos sobre as repercussões das atividades econômicas sobre o ambiente têm contribuído para se identificar atividades degradadoras. No entanto ainda são poucas as pesquisas que se utilizam das bacias hidrográficas como área de análise da fragilidade ambiental, principalmente em relação à Amazônia maranhense. Com isso, o objetivo deste artigo é apresentar dados sobre as áreas de maior e menor fragilidade ambiental da bacia do Córrego Água Branca, oeste maranhense. Para isso se utilizou da análise empírica baseada em dados de geologia, pedologia, geomorfologia, e usos e coberturas do solo, visando à identificação das áreas de maior fragilidade ambiental. Com a análise dos dados, percebeu-se que há a necessidade de que novas formas de gestão e seus respectivos processos de uso e ocupação da bacia sejam realizados, visando à redução da fragilidade emergente forte que representa $42,2 \%$ da área da bacia.
\end{abstract}

Palavras-chave: Degradação Ambiental; Bacia Hidrográfica; Uso e Cobertura do Solo.

\section{ENVIRONMENTAL FRAGILITY IN STREAM BASIN ÁGUA BRANCA, WEST OF MARANHÃO \\ ABSTRACT}

The studies on the effects of economic activities on the environment have contributed to identify activities degradetions. However there are few studies that use of catchment basins as area of analysis of the environmental fragility, particularly in relation to the Amazon. With this, the objective of this paper is to present data on the areas of greatest and least environmental fragility of the basin of the Água Branca, west of Maranhão, Brazil. To do this if you have used the empirical analysis based on data from geology, pedology, geomorphology, and uses and soil cover, aiming to identify the areas of greatest environmental fragility. With the analysis of the data, it was found that there is a need for new forms of management, and their respective procedures for use and occupation of the basin are conducted, aiming at the reduction of fragility strong emerging which represents $42.2 \%$ of the area of the basin.

Keywords: Environmental Degradation; Watershed; Use and Soil Cover.

\section{LA FRAGILIDAD DEL MEDIO AMBIENTE EN LA CUENCA DEL ARROYO DE AGUA BLANCA, AL OESTE DE MARANHÃO}

\section{RESUMEN}


Los estudios sobre los efectos de la actividad económica sobre el medio ambiente han contribuido a identificar actividades degradantes. Sin embargo, existen pocos estudios que utilizan de las cuencas hidrográficas como ámbito de análisis de la fragilidad ambiental, particularmente en relación a la Amazonía. Con esto, el objetivo de este trabajo es presentar los datos sobre las áreas de mayor y menor fragilidad ambiental de la cuenca del Água Branca, oeste maranhense. Para ello si ha utilizado el análisis empírico basado en datos de la geología, la edafología, la geomorfología, y uso y cobertura del suelo, con el objetivo de identificar las áreas de mayor fragilidad ambiental. Con el análisis de los datos se comprobó que existe una necesidad de nuevas formas de gestión, y sus respectivos procedimientos para el uso y la ocupación de la cuenca se lleven a cabo, encaminadas a la reducción de la fragilidad emergente sólida que representa el 42,2\% del área de la cuenca.

Palabras clave: La Degradación Ambiental; Cuenca Hidrografica; Uso y Cobertura del Suelo.

\section{INTRODUÇÃO}

A problemática ambiental encontra-se entre os temas de maior destaque nas instituições de pesquisa e na mídia em geral. Leff (2007, p. 191) destaca que "a crise ambiental é a crise do nosso tempo". O mesmo autor ainda menciona o fato de que a resolução desta "crise" pauta-se numa busca pelo melhor conhecimento das ações realizadas pelo homem sobre a natureza.

Como destaca Ross (2005, p. 14), as modificações realizadas pelo homem “[...] alteram o equilíbrio de uma natureza que não é estática, mas que apresenta quase sempre um dinamismo harmonioso em evolução estável e contínua". Desse modo, é necessário o conhecimento do ambiente físico, dos contextos histórico-culturais e das atividades econômicas encontradas em determinadas áreas. Pois, como destaca Ross (1994), entender a inter-relação entre estes processos auxilia no conhecimento da fragilidade ambiental do ambiente, principalmente quando se trata do estudo de bacias hidrográficas.

No entanto, os projetos estatais que objetivam a disseminação e redistribuição espacial de atividades econômicas, em especial as ligadas à indústria, têm impulsionado a degradação ambiental em todo o mundo. No caso da porção oeste do território maranhense, tem-se que a construção das rodovias BR 010 (Belém-PA/Brasília-DF) e BR 222 (Marabá-PA/Fortaleza-CE), e das ferrovias Carajás (Carajás/São Luís) e Norte-Sul (atualmente pronta entre Palmas-TO e Açailândia-MA), a tornaram propícia à implantação de grandes projetos industriais e agropecuários.

Nas proximidades dos entroncamentos das rodovias e ferrovias citadas têm-se a bacia do Córrego Água Branca $\left(258 \mathrm{~km}^{2}\right)$. Esta abrange porções dos territórios dos municípios de Açailândia-MA (186,5 km²), Cidelândia $\left(5 \mathrm{~km}^{2}\right)$, Imperatriz $\left(1,5 \mathrm{~km}^{2}\right)$ e São 
Fragilidade ambiental na bacia do córrego Água Branca, Oeste maranhense Raifran Abidimar de Castro

Francisco do Brejão $\left(65 \mathrm{~km}^{2}\right)$ (Figura 01). Esta necessita de estudos que analisem sua fragilidade ambiental, devido à intensa modificação do uso realizada nas últimas décadas. Portanto, o objetivo deste artigo é disponibilizar informações sobre as áreas de maior e menor fragilidade ambiental da bacia do Córrego Água Branca.

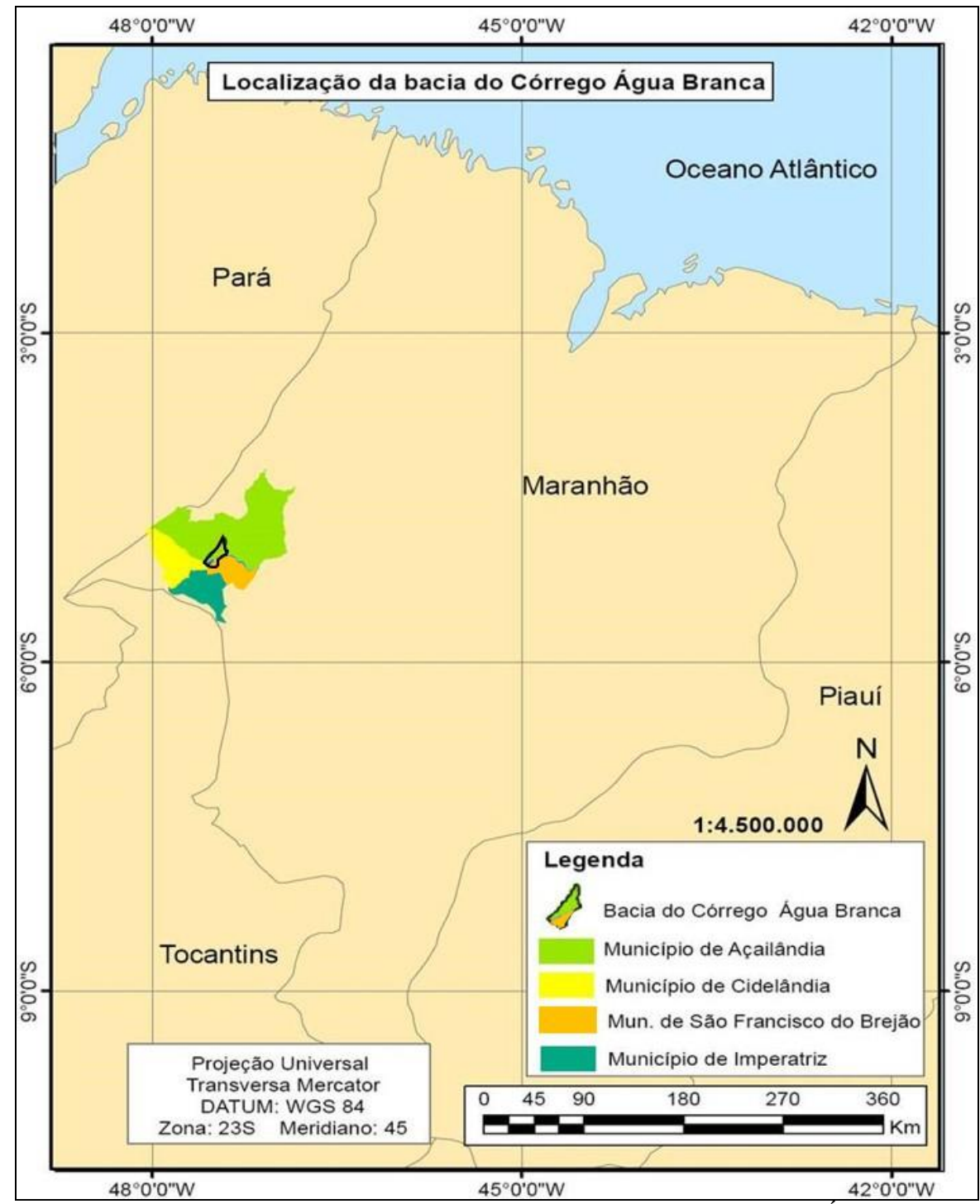

Figura 1 - Mapa de localização da área de estudo - Bacia do Córrego Água Branca Fonte: Dados da pesquisa. Org. e elaboração: CASTRO, 2009.

\section{MATERIAIS E MÉTODOS}

Para a análise empírica da bacia do Córrego Água Branca utilizou-se a metodologia descrita por Ross (1994), que se baseia na compreensão das características e da dinâmica do ambiente natural, bem como do meio socioeconômico. $O$ autor (op. cit.) divide a fragilidade ambiental em "Potencial", quando se consideram apenas as características físicas 
da bacia, principalmente pedologia e geomorfologia, e "Emergente" quando se somam as ações antrópicas à primeira.

Os dados geológicos e geomorfológicos foram coletados entre os anos de 2008 e 2009. Para isto foram utilizadas as cartas geológicas da CPRM (Serviço Geológico do Brasil), Folhas Açailândia (SB.23-V-A) e Imperatriz (SB.23-V-C) na escala de 1:250.000. Os dados geológicos e pedológicos foram plotados e trabalhados no ArcGis 9.2®, gerando um mapa na escala de 1:250.000. Seguindo-se a classificação geomorfológica de Florenzano (2008), gerou-se outro mapa na mesma escala dos demais.

O mapeamento multitemporal da cobertura e uso do solo da bacia ocorreu com o uso de imagens de satélite Landsat 5 - TM, Zona 23, Meridiano 45, órbitas/ponto 222/63 e 222/64. A seleção das datas das imagens seguiu o critério da completa ausência de nuvens nas composições de bandas 3B, 4G e 5R. O mapeamento da declividade e da hipsometria foi realizado utilizando-se as cartas da CPRM citadas. Em seguida, complementando-se com as imagens Shuttle Radar Topographic Mission (SRTM), através do software ArcGis 9.2®.

\section{AS BACIAS HIDROGRÁFICAS, O GEOPROCESSAMENTO E A DEGRADAÇÃO AMBIENTAL}

A questão conceitual sobre bacias hidrográficas já foi estudada por diversos autores. Merecem destaque os estudos clássicos de Santos (2005), Rocha (1991), Bertoni e Lombardi Neto (1990). Em relação ao conceito, para Silveira (1997), bacia hidrográfica é uma área de captação natural da água da precipitação que faz convergir os escoamentos para um único ponto de saída, sendo que esta é constituída de um conjunto de vertentes e de uma rede de drenagem que confluem em um único leito principal.

Para Botelho e Silva (2004), a bacia hidrográfica, adotada como célula básica de análise ambiental, permite conhecer e avaliar seus diversos componentes e os processos e interações que nela ocorrem. Ross e Del Prete (1998) afirmam ainda que a bacia hidrográfica pode ser considerada uma unidade hidrogeomorfológica da paisagem, com seus canais fluviais, saídas e divisores que acabam por constituir um importante geoecossistema.

Sobre as alterações provocadas no solo, Almeida e Tertuliano (1999) destacam que sob condições onde a cobertura vegetal ainda está presente, os restos vegetais que são transferidos ao solo podem influir sobre fatores diversos, dentre eles o armazenamento de água e a temperatura do solo. Para Fendrich et al. (1997, p. 46), as principais agressões 
causadas pelo homem decorrem da retirada da cobertura vegetal, da agricultura sem manuseio adequado, das áreas de pastagem com altas densidades de animais, da abertura de estradas sem execução de obras de drenagem, dentre outros. Processos que podem ser mais bem estudados com o auxílio das técnicas de geoprocessamento.

Segundo Guerra (1999), as voçorocas estão associadas a processos de erosão acelerada, e, portanto, com a instabilidade da paisagem. Por isso, o uso de técnicas de mapeamento desta diversidade de atividades, bem como sua correlação com os mapas que identificam a localização dos processos de degradação, tem sido amplamente utilizado em pesquisas e no acompanhamento de fenômenos ambientais. Segundo Xavier-da-Silva e Zaidan (2004), na pesquisa ambiental algumas proposições merecem destaque, que são: o fato de que todos os fenômenos são passíveis de serem localizados; de terem uma extensão determinável; de estarem em constante alteração; e de que todo fenômeno apresenta relacionamentos, portanto, nunca isolado. Temática que se relaciona com a visão sistêmica de análise ambiental.

Para Christofoletti (1999), a aplicação da abordagem sistêmica aos estudos na Geografia serviu para melhor focalizar as pesquisas e para delinear com maior exatidão o setor de estudo desta ciência. Segundo Bertrand (2004), a paisagem não é a simples adição de elementos disparatados, numa determinada porção do espaço. Ele destaca que ela é o resultado da combinação dinâmica de elementos físicos, biológicos e humanos, que reagindo dialeticamente uns sobre os outros resultam nas características de uma área. Processos que, ao serem analisados cuidadosamente, possibilitam um maior conhecimento sobre as atividades que podem ser estabelecidas sobre uma área, e principalmente a alteração de usos que visam à melhoria da qualidade ambiental desta.

Neste sentido, Tricart (1977) analisa o ambiente sobre o prisma da Teoria Geral dos Sistemas, e parte dos pressupostos de que na natureza as forças de energia e matéria se processam através de relações de equilíbrio dinâmico. Segundo Ross (1994), as "Unidades Ecodinâmicas Estáveis", apesar de estarem em equilíbrio dinâmico, apresentam Instabilidade Potencial qualitativamente previsível, face as suas características naturais e possível inserção antrópica. Destas considerações teóricas se amplia a base de estudos das bacias hidrográficas a partir do estudo das fragilidades ambientais, neste caso específico, da bacia do córrego Água Branca.

\section{RESULTADOS E DISCUSSÃO}


A geologia da bacia é constituída por terrenos do Cretáceo Superior da Formação Itapecuru, do Terciário Inferior da Formação Ipixuna e do Terciário Superior do Grupo Barreiras. O primeiro enquadra-se no domínio das coberturas sedimentares mesozoicas; e os dois últimos no domínio geológico das coberturas sedimentares cenozoicas (DNPM/CPRM, 1990).

A bacia do córrego Água Branca, com $258 \mathrm{~km}^{2}$, corresponde a uma hierarquia fluvial de $3^{\text {a }}$ grandeza. Apresenta 24 cursos d'água que somam um comprimento total de $123,4 \mathrm{~km}$, com uma densidade de cursos d'água de $0,07 \mathrm{~km}^{2}$. Tem uma densidade de drenagem de $0,47 \mathrm{~km} / \mathrm{km}^{2}$, com a distribuição dos principais afluentes localizando-se principalmente na margem direita.

A geomorfologia foi subdividida nas seguintes classes: "Relevo Plano" com formas tabulares e vertentes suavemente inclinadas $\left(122 \mathrm{~km}^{2}\right)$; "Relevo Suave Ondulado" com colinas de topo convexo e vertentes de declividade suave $\left(95 \mathrm{~km}^{2}\right)$; "Relevo Ondulado" com morros com topos geralmente conservados, apresentando altas declividades e, em alguns casos, vertentes escarpadas $\left(41 \mathrm{~km}^{2}\right)$.

De acordo com levantamentos realizados pela Superintendência do Desenvolvimento da Amazônia - Projeto de Hidrologia e Climatologia da Amazônia (SUDAM/PHCA, 1984), que segue a classificação climática de Thornthwaite, a área da bacia corresponde à tipologia climática $\mathrm{C} 2 \mathrm{r}$ A' a', sendo: $\mathrm{C} 2=$ clima úmido; $\mathrm{r}=$ pouca ou nenhuma deficiência de água; A'= índice de eficiência térmica maior que $1140 \mathrm{~mm}$; e a' = eficiência térmica de concentração no verão sempre inferior a $48 \%$.

Estudos realizados por Marçal (2000), considerando-se a área da bacia aqui estudada, indicam que os solos predominantes na área são o Latossolo Vermelho-Amarelo e o Argissolo Vermelho Amarelo. O grupo dos Latossolos com $113 \mathrm{~km}^{2}$, representando $44 \%$ da área, apresenta uma fração granulométrica mais arenosa. Por outro lado, o grupo dos Argissolos, com $145 \mathrm{~km}^{2}$ da área da bacia, apresenta uma fração granulométrica mais argilosa.

Em relação aos principais tipos de cobertura e uso na área da bacia nos anos de 1988, 1999 e 2008, seguem os dados demonstrados nas Tabelas 01, 02 e 03, respectivamente. Destes dados destacam-se: a intensa redução da capoeira nestes vinte anos; a intensificação da expansão silvicultora a partir de 1999; uma aceleração no aumento da área destinada à pastagem; há um crescimento do solo exposto entre 1988 e 1999, mas observa-se uma redução entre 1999 e 2008, pois em alguns casos houve o crescimento de pastagem nestas áreas. 
Fragilidade ambiental na bacia do córrego Água Branca, Oeste maranhense Raifran Abidimar de Castro

Tabela 1 - Tipos de cobertura e uso da bacia do córrego Água Branca/1988

\begin{tabular}{ccc}
\hline Classes de Uso & Área $\mathbf{~ e m ~} \mathbf{k m}^{2}$ & Porcentagem \\
\hline Capoeria & 66,4 & 25,73 \\
Capoeira e Pastagem & 35,7 & 13,83 \\
Núcleo Urbano & 0,2 & 0,12 \\
Pastagem & 154,2 & 59,76 \\
Povoado & 0,4 & 0,15 \\
Solo Exposto & 1,1 & 0,42 \\
\hline
\end{tabular}

Fonte: Dados da pesquisa. Org.: CASTRO, 2009.

Tabela 2 - Tipos de cobertura e uso da bacia do córrego Água Branca/1999

\begin{tabular}{ccc}
\hline Classes de Uso & Área $\mathbf{e m ~ k m}^{2}$ & Porcentagem \\
\hline Agrovila & 1,2 & 0,16 \\
Capoeria & 64,3 & 24,92 \\
Capoeira e Pastagem & 22,2 & 8,6 \\
Núcleo Urbano & 2,3 & 0,96 \\
Pastagem & 156,3 & 60,58 \\
Povoado & 1,4 & 0,54 \\
Solo Exposto & 2,1 & 0,81 \\
Silvicultura & 8,2 & 3,13 \\
\hline
\end{tabular}

Fonte: Dados da pesquisa. Org.: CASTRO, 2009.

Tabela 3 - Tipos de cobertura e uso da bacia do córrego Água Branca/2008

\begin{tabular}{ccc}
\hline Classes de Uso & Área $\mathbf{~} \mathbf{~ k m} \mathbf{~ k m}^{2}$ & Porcentagem \\
\hline Agrovila & 2,6 & 1,4 \\
Capoeria & 48,8 & 18,91 \\
Capoeira e Pastagem & 15,7 & 6,08 \\
Núcleo Urbano & 4,6 & 1,78 \\
Pastagem & 166,7 & 64,61 \\
Povoado & 2,9 & 1,12 \\
Solo Exposto & 0,9 & 0,34 \\
Silvicultura & 15,8 & 6,12 \\
\hline
\end{tabular}

Fonte: Dados da pesquisa. Org.: CASTRO, 2009.

Sobre a evolução dos usos e cobertura também merecem destaque os seguintes dados: a capoeira, classe que mais tem contribuído para a proteção do solo da bacia desde que sua cobertura original foi retirada, teve uma redução de 25,73\% no ano de 1988 para 18,91\% em 2008. Mas observa-se o agravante de que a classe "Pastagem" cresceu de $59,76 \%$ para $64,61 \%$ no mesmo período. Neste caso, diminuiu-se a quantidade de solo protegido de erosões pluviais e aumentou-se a área exposta ao pisoteio do gado e à formação de ravinas. Estas podem evoluir para voçorocas, caso não sejam realizados trabalhos de contenção.

Deve-se mencionar o fato da ampliação da silvicultura de eucalipto. Esta cultura não existia ainda nas primeiras datas do levantamento (1988 e 1999), mas em 2008 já representava $6,12 \%\left(15,8 \mathrm{~km}^{2}\right)$ da área da bacia. Este é apenas um pequeno exemplo diante do grande crescimento que este tipo de atividade tem apresentado em toda a porção oeste do Maranhão. 
Os Latossolos caracterizam-se por serem solos profundos e bem drenados. Áreas com este tipo de solo, associado a declividades de 0 a $6 \%$, foram classificadas como de "Fragilidade Potencial Muito Fraca" (Tabela 04). Este mesmo solo associado a declividades entre $07 \%$ e $12 \%$ foram enquadradas na classe denominada "Fraca". As áreas com este tipo de solo e declividades entre 13 e 20\%, foram enquadradas como áreas com "Média Fragilidade Potencial".

Tabela 4 - Principais características das classes de Fragilidade Potencial

\begin{tabular}{cc}
\hline Classes & Principais Características \\
\hline Muito Fraca & Latossolo Vermelho Amarelo, com declividade até 6\% \\
Fraca & Latossolo Vermelho Amarelo, com declividade entre $7 \%$ e $12 \%$ \\
Média & Latossolo Vermelho Amarelo, com declividade entre $13 \%$ e $20 \%$ \\
Forte & Argissolo Vermelho Amarelo, com declividade entre 0 e $12 \%$ \\
Muito Forte & Latossolo Vermelho Amarelo, com declividade acima de $20 \%$; e \\
& Argissolo Vermelho Amarelo com declividade acima de $12 \%$. \\
\hline Fonte: Dados da pesquisa. Org.: CASTRO, 2009.
\end{tabular}

Conforme pode ser observado na Tabela 04, a classe de fragilidade com maior área de abrangência na bacia é a denominada de "Fragilidade Forte". Esta classe representa 128,3 $\mathrm{km}^{2}$ da área da bacia. Destaca-se também a área de abrangência da classe "Muito Fraca" com 106,7 km². A maior ocorrência destas é justificada pela grande abrangência de áreas com menor declividade, ou seja, de 0 a 12\% (96\% da bacia) nos dois tipos de solos. É importante citar também que, segundo Marçal (2000) e Ross (1994), o Argissolo apresenta maior fragilidade, sendo o mesmo classificado como de "Fragilidade Potencial Forte", quando associado a declividades entre 0 e $12 \%$.

Os Argissolos apresentam drenagem inferior, principalmente a partir de $40 \mathrm{~cm}$ de profundidade. Este processo amplia a possibilidade de ocorrência de processos erosivos, informação destacada por Marçal (2000). Portanto, áreas com este tipo de solo associado a declividades de 0 a 12\% foram classificadas com "Fragilidade Potencial Forte". Quando a ocorrência deste solo está associada a declividades acima de 12\% estas áreas foram nomeadas com "Fragilidade Potencial Muito Forte". Esta última classe também enquadra as áreas com Latossolo e declividade acima de $12 \%$. Na Tabela 05 se apresentam a porcentagens de cada nível de "Fragilidade Potencial" encontrada na bacia, bem como a representação cartográfica desta na Figura 02. 
Fragilidade ambiental na bacia do córrego Água Branca, Oeste maranhense Raifran Abidimar de Castro

Tabela 5 - Áreas e porcentagem das classes de Fragilidade Potencial

\begin{tabular}{ccc}
\hline Fragilidade Potencial & Área $\mathbf{~} \mathbf{~} \mathbf{~ K m}^{\mathbf{2}}$ & $\mathbf{\%}$ \\
\hline Muito Fraca & 106,7 & 37 \\
Fraca & 11,9 & 4,2 \\
Média & 9,6 & 3,4 \\
Forte & 128,3 & 45,1 \\
Muito Forte & 28,5 & 10,3 \\
\hline
\end{tabular}

Fonte: Dados da pesquisa. Org.: CASTRO, 2009.

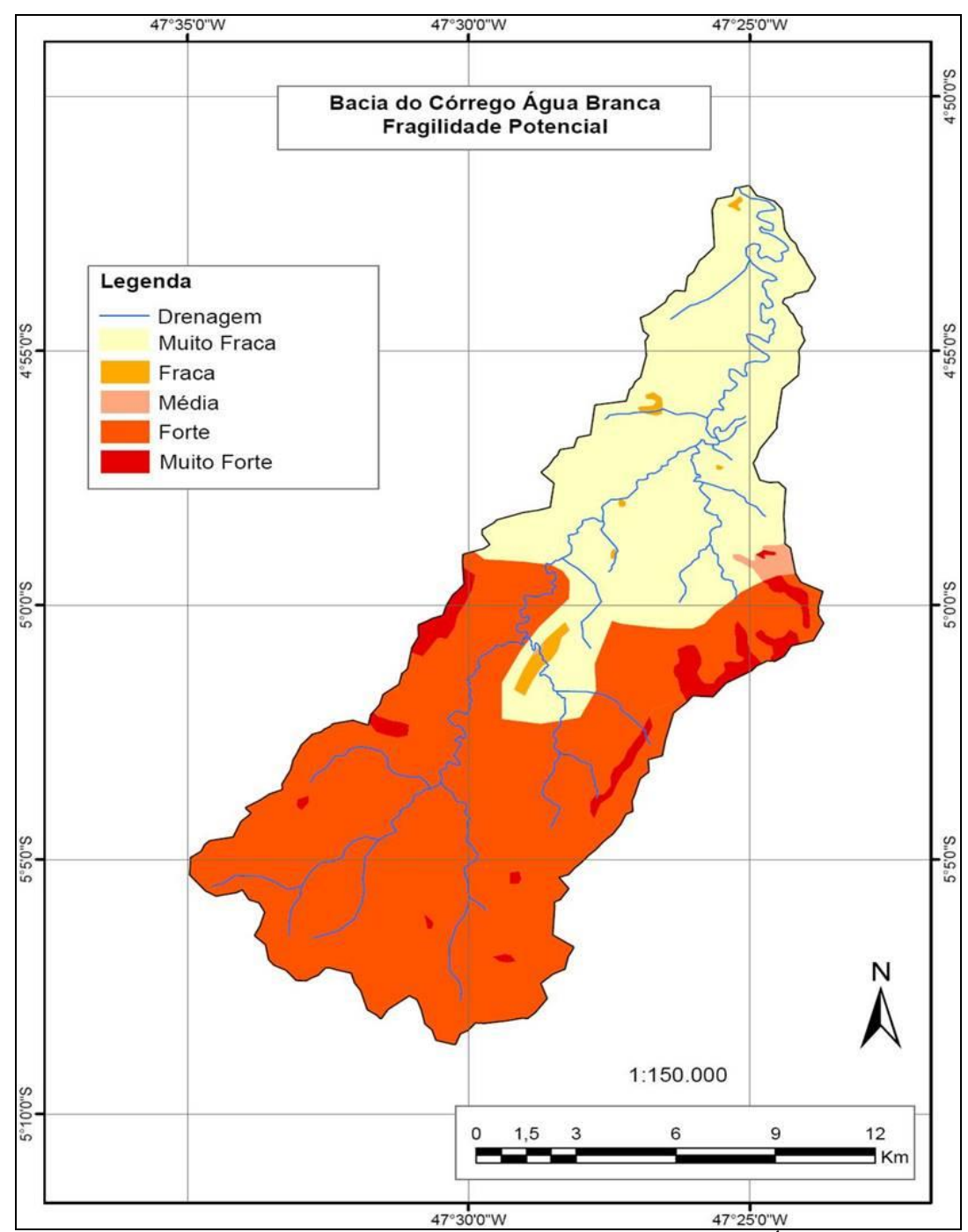

Figura 2 - Mapa da fragilidade Potencial da Bacia do Córrego Água Branca Fonte: Dados da pesquisa. Org. e elaboração: CASTRO, 2009.

No caso da "Fragilidade Emergente", com a caracterização das classes disposta na Tabela 06 e representada cartograficamente na Figura 03, tem-se a classe "Forte" com maior área de ocorrência, representando um total de $118,5 \mathrm{~km}^{2}$. Esta classe ocorre em toda a extensão da bacia, principalmente nos cursos alto e médio. Ocorre também uma área considerável no baixo curso, sendo que esta é caracterizada pela concentração de ferrovias, rodovia, estradas vicinais e com o curso do córrego densamente meandrante. O problema da concentração de diversas estradas vicinais ampliou a ocorrência da classe "Forte". 
Fragilidade ambiental na bacia do córrego Água Branca, Oeste maranhense Raifran Abidimar de Castro

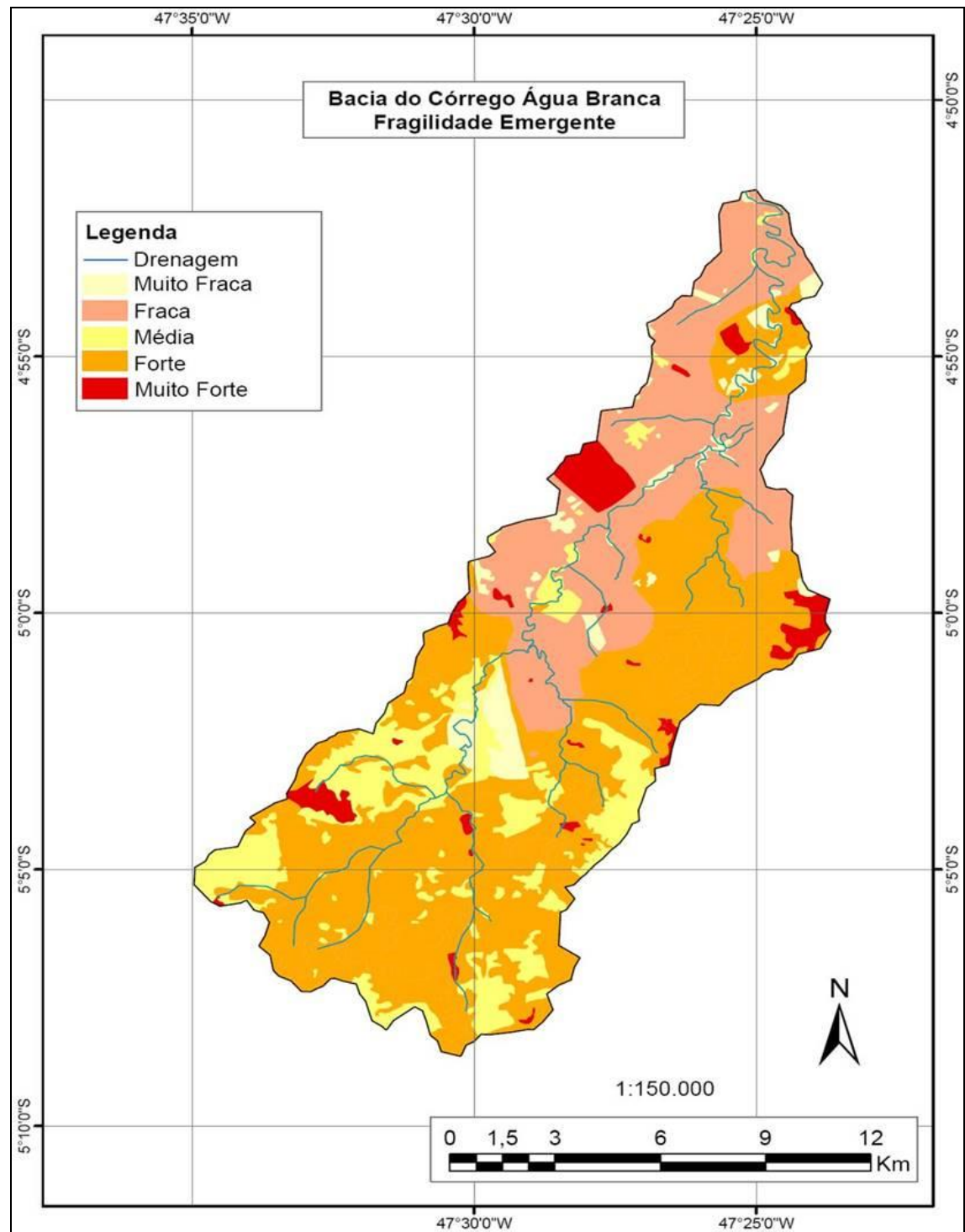

Figura 3 - Mapa da fragilidade Emergente da Bacia do Córrego Água Branca Fonte: Dados da pesquisa. Org. e Elaboração: CASTRO, 2009.

Tabela 6 - Principais características das classes de Fragilidade Emergente

\begin{tabular}{|c|c|}
\hline Classes & Principais Características \\
\hline Muito Fraca & Capoeira e silvicultura, declividade entre 0 e $6 \%$, e Latossolo. \\
\hline Fraca & $\begin{array}{c}\text { Pastagem bem conservada em declividades entre } 0 \text { e } 6 \% \text {; silvicultura em declividades } \\
\text { entre } 7 \% \text { e } 20 \% \text {, ambas em Latossolo. }\end{array}$ \\
\hline Média & $\begin{array}{l}\text { Capoeira, capoeira permeada por pastagens e pastagem em declividades até 13\% em } \\
\text { Latossolo; capoeira em declividades de até 12\%, em Argissolo. }\end{array}$ \\
\hline Forte & $\begin{array}{c}\text { Povoado; capoeira em declividades acima de } 12 \% \text { em Latossolo e Argissolo; pastagem e } \\
\text { capoeira permeada por pastagem, ambas em declividades acima de } 12 \% \text { em Latossolo, e } \\
\text { em declividades entre } 0 \text { e } 12 \% \text { em Argissolo; silvicultura em declividades acima de } 20 \% \\
\text { em Latossolo, e entre } 0 \text { e } 12 \% \text { em Argissolo. }\end{array}$ \\
\hline Muito Forte & $\begin{array}{l}\text { Solo exposto, agrovila e núcleo urbano; pastagem, capoeira permeada por pastagem e } \\
\text { silvicultura, todas com declividade acima de } 12 \% \text { em Argissolo. }\end{array}$ \\
\hline
\end{tabular}

Fonte: Dados da pesquisa. Org.: CASTRO, 2009.

Destaca-se que os núcleos urbanos presentes na área da bacia estão bem consolidados, como é o caso do bairro denominado Vila Ildemar, a noroeste da bacia, 
assim como as áreas rurais. Todavia, o uso sem planificação tem contribuído para que a fragilidade emergente se apresente diversificada na área da bacia. Com isso, apresentam-se na Tabela 07 as áreas e as porcentagens representativas de cada classe de "Fragilidade Emergente".

Tabela 7 - Áreas e porcentagem das classes de Fragilidade Emergente

\begin{tabular}{ccc}
\hline Fragilidade Emergente & Área $\mathbf{~ e m ~} \mathbf{~ k m}^{\mathbf{2}}$ & $\mathbf{0}$ \\
\hline Muito Fraca & 23,6 & 8,1 \\
Fraca & 69,2 & 24,4 \\
Média & 45,4 & 16 \\
Forte & 118,5 & 42,2 \\
Muito Forte & 28,3 & 9,3 \\
\hline
\end{tabular}

Fonte: Dados da pesquisa. Org.: CASTRO, 2009.

O baixo curso da bacia é representado em sua maior parte pela classe de "Fragilidade Emergente Fraca" com 69,2 km². Esta classe ocorre também no médio curso, principalmente a oeste desta área da bacia. A ocorrência da classe "Média" distribui-se por toda a extensão da bacia. Mas destaca-se o fato de $85 \%$ desta concentrar-se no Alto Curso, mesmo que permeada por da classe "Forte". Ao todo são $45,4 \mathrm{~km}^{2}$ de área, totalizando 16\% da bacia do Córrego Água Branca. Destaca-se que esta classe é caracterizada por: capoeira e capoeira permeada por pastagem e pastagem com declividade até $12 \% \mathrm{em}$ Latossolo; Capoeira com declividade de até 12\% em Argissolo.

A classe "Fragilidade Emergente Muito Fraca" ocorre distribuída em diversas áreas da bacia, principalmente no baixo curso. Destaca-se que $63 \%$ do total desta classe $(14,8$ $\mathrm{km}^{2}$ ) ocorre concentrada numa área de silvicultura com baixa declividade.

A classe "Fragilidade Emergente Muito Forte", com 9,3\% da área, também ocorre em diversas áreas devido à distribuição dos núcleos urbanos, da agrovila, dos diversos pontos de terras com solo exposto. Em alguns casos este solo exposto está associado à formação de erosões.

É importante citar que durante a realização desta pesquisa foram identificadas 10 áreas do curso do Córrego Água Branca que apresentam represamento. Esta é uma grave característica, pois a mesma altera o curso normal do córrego, causando desequilíbrios. Isto devido à maior evaporação da água ocasionada pela maior exposição aos raios solares; dentre outros fatores.

Destacam-se também os casos em que estes represamentos trazem riscos à população, pois os mesmos foram realizados para a construção de rodovias e estradas vicinais. Os cursos d'água correm sobre as estradas, e estas não apresentam a devida segurança. Estes riscos são ampliados nos períodos de chuvas (de novembro a maio), 
Fragilidade ambiental na bacia do córrego Água Branca, Oeste maranhense Raifran Abidimar de Castro

quando já foram registrados graves acidentes associados a deslizamentos, principalmente na BR 222.

\section{CONSIDERAÇÕES FINAIS}

É evidente que esta pesquisa não deve ser usada como único referencial para as ações de controle ambiental a serem utilizadas para o correto manejo ambiental da bacia, na medida em que o gerenciamento ambiental de uma bacia hidrográfica implica em análises muito mais complexas e elaboradas. Neste sentido, cabe destacar que, além dos dados produzidos por esta pesquisa, são necessários outros estudos complementares que englobem outros focos de atuação na linha ambiental.

Pesquisas que considerem os aspectos socioeconômicos, culturais e educacionais são necessárias, visto que os resultados aqui apresentados podem estar relacionados à intensidade de consumo, com o maior ou menor grau de consciência ambiental da população local; e principalmente com os projetos de desenvolvimento regional, neste caso o Programa Grande Carajás (PGC), no qual a área desta bacia é abrangida.

Como foi destacado nos resultados, a "Fragilidade Ambiental Emergente" na classe "Forte" tem grande abrangência na área da bacia. Isto se deve principalmente à redução da proteção do solo em área com declividade acentuada. Problemática que deve ser cuidadosamente analisada para que projetos de recuperação ao menos da capoeira sejam realizados, para uma maior proteção do solo.

\section{AGRADECIMENTOS}

Ao Instituto Federal do Maranhão (IFMA); ao Programa de Incentivo à Qualificação dos Docentes do IFMA (PROQUALIS/IFMA); ao Grupo AB'Saber

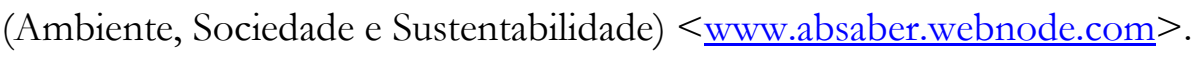

\section{REFERÊNCIAS}

ARCGIS/ARCINFO - Esri Inc. ArcGis, Version 9.2. New York: Environmental Systems Research Institute, Inc., 2008. 1 Cd Rom.

ALMEIDA, Josimar Ribeiro; TERTULIANO, Marcos Farias. Diagnose dos sistemas ambientais: métodos e indicadores. In: CUNHA, Sandra Batista; GUERRA, Antônio José 
Fragilidade ambiental na bacia do córrego Água Branca, Oeste maranhense Raifran Abidimar de Castro

Teixeira (Org.). Avaliação e Perícia Ambiental. Rio de Janeiro: Bertrand Brasil, 1999. p. $115-172$.

BERTONI, José; LOMBARDI NETO, Francisco. Conservação do solo. São Paulo: Ícone, 1990.

BERTRAND, George. Paisagem e geografia física global: esboço metodológico. Revista Ra'e Ga, Curitiba, n. 08, p. 141-152, 2004.

BOTELHO, Rosângela Garrido Machado; SILVA, Antônio Soares. Bacia Hidrográfica e Qualidade Ambiental. In: VITTE, Antônio Carlos; GUERRA, Antônio José Teixeira (Org.). Reflexões sobre a geografia física no Brasil. Rio de Janeiro: Bertrand Brasil, 2004. p. 153-192.

BRASIL. DNPM. Programa de Levantamentos básicos do Brasil. Projeto Especial Mapas de Recursos Minerais de Solos e de Vegetação para a área do Programa Grande Carajás. Folha Açailândia SB.23-V-A, escala 1:250.000.

Programa de Levantamentos básicos do Brasil. Projeto Especial Mapas de Recursos Minerais de Solos e de Vegetação para a área do Programa Grande Carajás. Folha Imperatriz SB.23 -V-C, escala de 1:250.000.

CHRISTOFOLETTI, Antônio. Modelagem de Sistemas Ambientais. São Paulo: Edgard Blucher, 1999.

Geomorfologia. 2. ed. São Paulo: Edgard Blucher, 1981.

FENDRICH, Roberto; OBLANDEM, Nicolau Leopoldo; AISSE, Miguel Mansur; GARCIAS, Carlos Mello. Drenagem e controle da erosão urbana. 4. ed. Curitiba: Champagnat, 1997.

FLORENZANO, Tereza Gallotti. Sensoriamento remoto para Geomorfologia. In: . (Org.). Geomorfologia: conceitos e tecnologias atuais. São Paulo: Oficina de Textos, 2008, p. 12-35.

GUERRA, Antônio José Teixeira. O início do processo erosivo. In: ; BOTELHO, Rosângela Garrido Machado (Org.). Erosão e conservação dos solos: conceitos, temas e aplicações. Rio de Janeiro: Bertrand Brasil, 1999. p. 17-55.

LEFF, Enrique. Epistemologia ambiental. Tradução de Sandra Valenzuela e Revisão Técnica de Paulo Freire Vieira. 4. ed. São Paulo: Cortez, 2007.

MARÇAL, Mônica dos Santos. Suscetibilidade à erosão dos solos no alto curso do Rio Açailândia - MA. 2000. 208f. Tese (Doutorado em Geografia) - Departamento de Geografia, Universidade Federal do Rio de Janeiro, Rio de Janeiro, 2000.

ROCHA, José Sales Mariano. Manual de Manejo Integrado de Bacias Hidrográficas. 2. ed. Santa Maria: UFSM, 1991.

ROSS, Jurandyr Luciano Sanches. Geomorfologia, Ambiente e Planejamento. 8. ed. São Paulo: Contexto, 2005. 
Análise Empírica da Fragilidade dos Ambientes Naturais e Antropizados. Revista do Departamento de Geografia da USP, São Paulo, v. 8, p. 63-74, 1994.

; DEL PRETE, Marcos Estevan. Recursos Hídricos e as Bacias Hidrográficas: âncoras do planejamento e gestão ambiental. Revista do Departamento de Geografia da USP, São Paulo, v. 12, p. 88-121, 1998.

SANTOS, Roseli Ferreira. Planejamento Ambiental: teoria e prática. São Paulo: Oficina de Textos, 2005.

SILVEIRA, André Luis Lopes. Ciclo hidrológico e bacia hidrográfica. In: TUCCI, Carlos Eduardo Morelli (Org.). Hidrologia: Ciência e Aplicação. 2. ed. Porto Alegre: Editora da UFRGS/ABRH, 1997. p. 35-51.

SUDAM/PHCA. Atlas Climatológico da Amazônia Brasileira. Superintendência de Desenvolvimento da Amazônia. Projeto de Hidrologia e Climatologia da Amazônia, Belém, 1984. $125 \mathrm{p}$.

TRICART, Jean. Ecodinâmica. Rio de Janeiro: FIBGE, 1977.

XAVIER-DA-SILVA, José; ZAIDAN, Ricardo Tavares. Geoprocessamento aplicado ao zoneamento de áreas com necessidade de proteção: o caso do parque estadual do IbitipocaMG. In: (Org.) Geoprocessamento e análise ambiental. Rio de Janeiro: Bertrand Brasil, 2004. p. 31-66. 